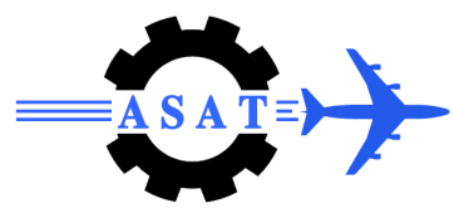

\title{
Experimental Investigation of the Effect of Air Injection into Inlet Air Manifold on the Transient Performance of Turbocharged Compression Ignition Engine at Different Operating Conditions
}

\author{
$\{\text { N. Elksas, A. El Maihy, A. Rashad, M. Fayed }\}^{*}$
}

\begin{abstract}
In this work, an experimental investigation was conducted in order to study the effect of air injection into inlet air manifold on the transient performance of turbocharged diesel engine at different operating conditions. The experimental work was performed on a test rig comprising a four stroke 5.67 liters water-cooled turbocharged diesel engine and a Heenan hydraulic dynamometer. Instrumentation included devices for measuring engine speed, load, exhaust smoke level, turbocharger speed, and inlet air manifold pressure. The test facility was provided with a computer controlled data acquisition system to enable fast and accurate measuring and evaluating the engine response to sudden demand of increased load or speed. The air injection system was designed, manufactured and erected on the engine to permit air injection at 2, 4, and 6 bar into the sir inlet manifold. The effect of air injection at different injection pressure was investigated when the engine is subjected sudden acceleration demands from $1000 \mathrm{rpm}$ to the target speed corresponding to maximum rack travel at initial loads of 10,30 and 50\%. Also, the effect of air injection at different injection pressure was investigated when the engine is subjected sudden load when the fuel pump control lever was locked at its initial setting at initial speed of $2000 \mathrm{rpm}$ and initial load of 20, 40 and 50\% from the engine full load then the load was increased suddenly to its maximum value. It is shown that the response time at which the engine speed reach to the desired value correspond to full fuel pump rack position decreases with the increase of the air injection pressure at different initial loads. Also it was noticed that the response time at which the engine load reach to the engine maximum load decreases with the increase of air injection pressure at different initial loads.
\end{abstract}

Keywords: Turbocharged diesel engine - Transient performance - Load acceptance Acceleration - Air injection

\section{Introduction}

Diesel engines enjoy better fuel economy, compared to petrol engines, especially at part load. This has lead to the wide spread application of diesel engines in heavy duty trucks and power generating units. Engine designers have been faced with the increasing demands for higher specific power, improved fuel consumption and lower exhaust smoke emission. Turbocharging offers such requirements.

In various diesel engine applications (e.g. vehicles, marine propulsion, and electrical generation) the turbocharger and the engine are optimized to achieve the rated power and maximum torque output.

\footnotetext{
Egyptian Armed Forces, Egypt.
} 
In automotive applications the matching is usually achieved for steady-state conditions and low specific fuel consumption. Thus, the turbocharger size is determined for high torque output, which usually leads to high moment of inertia and consequently slow air charge response. Quick changes in rack position do not result in instantaneous response of the turbocharger, due to its inertia and compressibility of the exhaust gas with the engine[1].

Thus the air-fuel ratio quickly decreases to a very low value and the mixture causes incomplete combustion; although much quantity of fuel can be rapidly injected into the cylinders, the turbocharger is slow to respond and provide a corresponding increase in air for the combustion. For this reason, a study on the investigation and the improvement of transient performance is to be a very important. Solutions to the problems involved must introduce satisfactory results at engine steady as well as transient operation. These solutions should also offer improvements to the performance of the turbocharged engine.Rakopoulos and Giakoumis [2] carried out an intensive review of the different simulations conducted to study turbocharged diesel engine transient performance and different ways used to improve it. It was concluded that transient diesel engine simulation has not yet adequately been diversified from steady-state/linear approximations, the most notable ones being the fuel pump and turbocharger modeling. Moreover, the simulations often fail to give insight into the highly complicated combustion performance during the early cycles of the transient event. Detailed friction, fuel pump and multi-cylinder modeling were identified as important aspects for more accurate transient simulation.

Several methods had been studied for improving transient response. Winterbone [3] categorized the methods of improving transient response as either 'passive' ones, i.e. those that do not require a separate energy source, or 'active' ones, i.e. those, which require an external energy source, such as electrical or hydraulic assistance. All researchers agreed on the importance of improving the transient response of turbocharged engine. The fundamental and parametric studies that were carried out had shed light into the basic engine and turbocharger variables development, and identified several means of improving response, such as decreased turbocharger inertia [4], variable geometry turbines [5: 7], power assisting systems [8: 10], tuned manifolds[11 and 12]. Unfortunately, some of the proposed techniques were effective for a limited engine operating range, e.g. tuned manifolds. Others, such as retarded injection timing or early opening of exhaust valves, conflict with important engine specifications (exhaust emissions or fuel consumption). Others need complicated installations and require high cost such as power assisting methods. Other methods impose certain modifications of actual turbochargers (of waste gated or variable geometry type) that are in general compromising their operation at engine partial loads.

It has not been yet established what would be the most successful strategy of improving transient response of diesel engine and their turbo charging systems. Given the ever changing design targets and the important research resources devoted to the development of diesel engines it can be expected that the search for new strategies will continue and the existing solutions will further be optimized.

Air-injection through the inlet manifold has been proposed as an effective technique because, in this case, the increased engine torque was instantly available due to the increase of volumetric efficiency [1]. Moreover it does not need a complicated modifications to be installed on the engine especially air compressor and air storage tanks are already exist in most applications using diesel engine as a prime over. Air injection, as a mean to improve the transient performance of turbocharged diesel engine, was used to inject air into the compressor rotor by Winterbone [2], ledger[13], and Boy [14] by experimentally validated simulation . Injection of air into the inlet manifold was studied experimentally by Fayed [15], 
Lee et al [16] and Gilkes et al [17,18]. Fayed studied the transient response improvement during acceleration and sudden load increase, Lee did not study effect of air injection during sudden load application. Gilkes et al performed their studies using computer simulation only.

The present work extends fayed work to study the effect of the quantity of air injected into the inlet manifold on the transient performance of turbocharged diesel engine.

The purpose of this paper was to investigate the effect of air injection into the intake manifold near the intake port at the compressor exit on the engine and turbocharger during the rapid acceleration and applying sudden load of the at different operating conditions. The effect of the injection pressure of air injected into the intake manifold on the factors of response performances such as turbine inlet temperature, compressor exit pressure, turbocharger speed, smoke level, engine load and engine speed are also discussed.

\section{Experimental Setup}

The experimental work was conducted on a complete rig (available in the laboratory of mechanical power and energy at the Military technical college for testing naturally aspirated as well as turbochargerd diesel engines. The test rig includes the engine and all the instrumentation necessary for measuring and recording the operating parameters. An on-line data acquisition system is furnished to improve the speed and accuracy of data collection and recording. A transport diesel engine of type Mercedes-Benz with an open chamber is used. This is a four stroke 6-cylinder with $97 \mathrm{~mm}$ bore, $128 \mathrm{~mm}$ stroke, and 17:1 compression ratio. Detailed engine specifications are given in Tables (1-2).

Engine external loading was carried out by an ELZE /Heenan hydraulic dynamometer. The fluid used was water with which the maximum breaking power could reach $170 \mathrm{~kW}$ at 4000 $\mathrm{rpm}$. The engine and dynamometer shafts were directly coupled through a cardan shaft.

Table (1) Engine Technical Data

\begin{tabular}{ll}
\hline Make and Model & Mercedes 352 series, Natural aspirated, Diesel engine \\
\hline Compression ratio & $17: 1$ \\
\hline No. of Strokes & 4 \\
\hline No. of cylinder & 6 \\
\hline Arranging & In-line \\
\hline Cooling & Water \\
\hline Bore & $97 \mathrm{~mm}$ \\
\hline Stroke & $128 \mathrm{~mm}$ \\
\hline Combustion chamber & Open type, Direct Injection \\
\hline Cam shaft & Sided \\
\hline Speed range & $800-2800 \mathrm{rpm}$ \\
\hline Maximum power & $120 \mathrm{HP}$ at $2800 \mathrm{rpm}$ \\
\hline Maximum torque & $28 \mathrm{kp} . \mathrm{m}$ at $1600 \mathrm{rpm}$ \\
\hline Static injection & $23 \mathrm{CA}$ BTDC \\
\hline Firing order & 1536241 \\
\hline Min. compression pressure & $20 \mathrm{bar}$ at $150-200 \mathrm{rpm}$ \\
\hline Injector opening pressure & $200 \mathrm{bar}$ \\
\hline
\end{tabular}


Table (2) Turbocharger Data

\begin{tabular}{ll}
\hline Type & UK PAT, Air research Turbochargers Division \\
\hline Compressor Data: & \\
\hline Inlet diameter & $62 \mathrm{~mm}$ \\
\hline Outlet diameter & $40 \mathrm{~mm}$ \\
\hline Impeller type & Backward with splitter vanes \\
\hline Number of vanes & 16 \\
\hline Impeller eye diameter & $44 \mathrm{~mm}$ \\
\hline Turbine Data: & \\
\hline Inlet diameter & $64 \mathrm{~mm}$ \\
\hline Number of entry & double \\
\hline Number of vanes & 14 \\
\hline
\end{tabular}

The system of air injection into the intake manifold is composed of electrically driven compressor, air reservoir equipped with pressure gauge, regulator valve, rubber hose ended by a manual valve which is naturally closed, and stop watch. The nozzle for injecting air into the intake manifold is embedded in the hole of $7.6 \mathrm{~mm}$ diameter and $3 \mathrm{~mm}$ deep. Compressed air is injected into the intake manifold through the air nozzle by opening the manual valve to its fully opening position and closing it after $5 \mathrm{~s}$. The duration of air injection is held constant for all tests carried out. The duration of air injection was chosen to be $5 \mathrm{sec}$. in accordance with previous experimental work carried out by Lee et al, [16].

The test rig is fully instrumented in order to acquire experimental data as well as to monitor the engine operating conditions.. Figure (1) gives a general scheme of the complete test rig showing numbered locations where important pickups and transducers are positioned. a list of these locations and the corresponding measured parameter at each is given Table (3).

The Data Acquisition System consists of three main elements, national instrumentation BNC2120 connector panel, A national instrumentation PCI-MIO-16E-1 data acquisition card and a PC Computer with data acquisition software (Lab VIEW). . The data acquisition card is used to collect the measured data from the measuring instruments through the BNC connector panel either analog or digital directly or after amplification and converts the analog inputs to digital data which is then recorded by the computer under soft ware control.

Table (3): List of measuring locations and the parameter measured at each (Relevant to Fig.(1))

\begin{tabular}{cll}
\hline \hline Location & Measured Parameter & Measuring device \\
\hline \hline 1 & Engine speed & Shaft encoder \\
\hline 2 & Brake torque & Hydraulic dynamometer equipped with load cell \\
\hline 3 & Boost pressure & Pressure transducer \\
\hline 4 & Turbocharger speed & Photo-electric sensor \\
\hline 5 & Injection pump rack position & linear variable differential transformer (LVDT \\
\hline 6 & Smoke meter & Photo-electric technique \\
\hline 7 & Exhaust temperature & Thermo couple \\
\hline
\end{tabular}

\section{Test Procedure}

Experiments are carried out with air injection during the transient conditions of a rapid acceleration, and load acceptance tests and their results are compared with the response characteristics of a turbocharged diesel engine without air injection. The parameters measured under the transient operating conditions are engine speed, turbocharger speed, inlet 
manifold pressure and exhaust smoke level. They were fed to the data acquisition system which is operated and controlled via the computer facility. Lab View software was used in order to acquire and record the historical variation of each measured parameter during the transient operation of the engine. Data were thus recorded for a period of approximately 30 seconds from the beginning of each test.

\subsection{Acceleration Tests}

Prior to each test, the engine speed was set to $1000 \mathrm{rpm}$ at the pre-required brake load of 27 , 81 and 135 N.m which is corresponding to 10,30 and 50\% respectively from the engine full load. After a short warm up period, the governor control lever was quickly actuated to increase the engine speed to its maximum possible value. In the same time, compressed air is injected into the intake manifold through the air nozzle at the preset pressure of 2, 4 and 6 bar.. At the same instant, the measurement procedure is triggered in order to start data logging and recording. When data acquisition is finished, recorded values are reviewed and then saved for later analysis.

\subsection{Load Acceptance Tests}

Prior to each test, the engine speed was set to $2000 \mathrm{rpm}$ at the pre-required brake load of 27 , 81 and 135 N.m which is corresponding to 10,30 and 50\% respectively from the engine full load. After a short warm up period, the dynamometer water control tap was suddenly opened to increase the water flow rate and hence the brake torque. In the same time, compressed air is injected into the intake manifold through the air nozzle at the preset pressure of 2, 4 and 6 bar. At the same instant, the data acquisition system is triggered, recorded data during each test, are saved in a separate file for analysis and comparisons as discussed in the following sections.

\section{Results and Discussions}

During the critical early cycles of a load or speed increase event, turbocharger delay is reflected into slow build-up of compressor boost pressure and shortage of combustion air, resulting in fuel-air ratio overshoot and combustion deterioration. Air-injection through the inlet manifold has been proposed as an effective technique because, in this case, the increased engine torque was instantly available due to the increase of volumetric efficiency. Injection of air in the inlet manifold, and consequently to the engine cylinders minimizes the fuel limiter's effect in first cycles (phase I), thus allowing higher amounts of fuel to be injected without fear of smoke emissions. hence better combustion is expected, That, in return, increases the exhaust gas energy, hence turbine power, faster acceleration of the turbocharger shaft is established; the higher achieved rotational speed moves the compressor operating point towards higher boost pressure which also helps in improving the combustion. Hence, the transient event is expected to develop much faster and with lower amounts of emissions.

In this work compressed air is injected into the intake manifold through an air nozzle in the same time at which sudden speed or load changes are applied to the engine. Of particular importance in air-injection configurations, is the exact injection schedule, i.e., onset and duration of injection as well as the pressure of the injected. In all experiments carried out in this work, the onset and the duration of air injection are kept constant. The effect of the air injection pressure on the transient performance of turbocharged diesel engine is investigated by changing injection pressure from no air injection to 2, 4, and 6 bar respectively. 


\subsection{Acceleration Test Results}

Prior to each test, the engine speed was set to $1000 \mathrm{rpm}$ at the pre-required brake load of 27 , 81 and 135 N.m which is corresponding to 10,30 and 50\% respectively from the engine full load. After a short warm up period, the governor control lever was quickly actuated to increase the engine speed to its maximum possible value. In the same time, compressed air is injected into the intake manifold through the air nozzle at the preset pressure of 2, 4 and 6 bar. The measured performance parameters during the acceleration period are plotted in the figures.

The development of engine speed with time at different pressure of injected air for different initial load of 10,30 and 50\% are shown in figure ( $2 \mathrm{a}, \mathrm{b}$ and c) respectively.

The results show that when the air injection system is used the time taken for the system to reach a steady state is significantly reduced. This means that the air pressure going into the cylinders is higher at an earlier stage of the process. Following the air-fuel equivalence ratio was kept at adequately high values during the early cycles of the transient event, preventing combustion deterioration and establishing faster turbocharger response. As a result, the engine response time was decreases.

Results also show that as the air injection pressure increases the response time decreases; the response time decrease from $5 \mathrm{~s}$ at no air injection to 3.5 when air is injected at 6 bar when the initial load is preset at $10 \%$ and from $13 \mathrm{~s}$ at no air injection to $7 \mathrm{~s}$ at when the air is injected at 6 bar when the initial load was preset at 30\%. At higher initial load namely $50 \%$, the engine did not reach to its maximum speed due to the increase of resisting load quickly to a higher value which suppress the engine speed increase due to the decrease of the surplus torque (engine minus resisting torques). However the steady state speed at full rack travel increase from $1700 \mathrm{rpm}$ at no air injection to $2200 \mathrm{rpm}$ when air is injected at 6 bar.

In figure (3), the turbo charger speed reaches a maximum value before it reach to its steady state value at low initial load. The time needed for the turbocharger to reach its maximum speed is reduced from $4 \mathrm{~s}$ at initial load of $10 \%$ when No air is injected to $2 \mathrm{~s}$ when air is injected at 6 bar. Ay higher initial load namely 50\% the steady state turbocharger speed increases slightly from $47000 \mathrm{rpm}$ when no air injection to about 60000 when air is injected at 6 bar when the initial load is preset at $50 \%$ from its full load. The time needed for the turbocharger to reach to its steady state value of $47000 \mathrm{rpm}$ is about $10 \mathrm{~s}$ at no air injection, however the time needed to reach the same speed is reduced significantly when air injection is used which reveal a significant improving in the transient performance of the turbocharged engine under investigation.

The boost pressure in the inlet manifold is shown to follow the behavior of the turbocharger speed as shown in figure (4). The time needed to reach steady state value is shown to decrease as the injection pressure increases. Also the steady state pressure is shown to increase as the injection pressure increases this due to better combustion due to higher amount of air supplied to the engine especially at the early cycles of the transient event.

Figure (5) shows the effect of injection pressure on the exhaust smoke level at different initial loading during acceleration tests. Results shows that as the injection pressure increases, the reduction on the smoke level increases at all initial loading due the increase of the quantity of air during combustion. A reduction of $30 \%$ to $40 \%$ is noticed at injection pressure of 6 bar at different initial loading. 


\subsection{Load Acceptance Test Results}

Prior to each test, the engine speed was set to $2000 \mathrm{rpm}$ at the pre-required brake load of 27 , 81 and 135 N.m which is corresponding to 20,30 and 50\% respectively from the engine full load. After a short warm up period, the dynamometer water control tap was suddenly opened to increase the water flow rate and hence the brake torque. In the same time, compressed air is injected into the intake manifold through the air nozzle at the preset pressure of 2, 4 and 6 bar. The measured performance parameters during the acceleration period are plotted in the figures.

The development of engine speed with time at different pressure of injected air for different initial load of 20,30 and 50\% are shown in figure (6 a, b and c) respectively.

The results show that when the air injection system is used the time taken for the system to reach a steady state is significantly reduced. This means that the air pressure going into the cylinders is higher at an earlier stage of the process. Following the air-fuel equivalence ratio was kept at adequately high values during the early cycles of the transient event, preventing combustion deterioration and establishing faster turbocharger response. As a result, the engine response time was decreases. The higher the injection pressure, the lower the maximum speed droop and the shorter the recovery period up to the final equilibrium. The response time decrease from $10 \mathrm{~s}$ at no air injection to 5 when air is injected at 6 bar at all initial load. The effect of air injection is more significant when the step increase on load is higher (at 20\% initial loading) knowing that the final state is kept the same for all tests as shown previously.

In figure (7), the time needed for the turbocharger to reach its maximum speed is reduced from $6 \mathrm{~s}$ at initial load of $20 \%$ when no air is injected to $4 \mathrm{~s}$ when air is injected at 6 bar. Ay higher initial load namely $50 \%$, it is reduced from $3 \mathrm{~s}$ when no air is injected to $1 \mathrm{~s}$ when air is injected at 6 bar. The steady state turbocharger speed increases from $36000 \mathrm{rpm}$ when no air injection to about 40000 when air is injected at 6 bar due to better combustion and increased of energy available in the exhaust at the turbine entry. This reveals a significant improving in the transient performance of the turbocharged engine under investigation.

The boost pressure in the inlet manifold is shown to follow the behavior of the turbocharger speed as shown in figure (8). The time needed to reach steady state value of 0.15 bar at initial load of $20 \%$ when no injection is used decreases from $7 \mathrm{~s}$ to $3 \mathrm{~s}$ when air is injected at 6 bar to reach the same value. Also the steady state pressure is shown to increase as the injection pressure increases this due to better combustion due to higher amount of air supplied to the engine especially at the early cycles of the transient event.

Figure (9) shows the effect of injection pressure on the exhaust smoke level at different initial loading during load acceptance tests. Results show that as the injection pressure increases, the reduction on the smoke level increases at all initial loading. Smoke level reduction of $60 \%$ is noticed at injection pressure of 6 bar.

\section{Conclusions}

In this work compressed air is injected into the intake manifold through an air nozzle in the same time at which sudden speed or load changes are applied to the engine. Of particular importance in air-injection configurations, is the exact injection schedule, i.e., onset and duration of injection as well as the pressure of the injected. In all experiments carried out in this work, the onset and the duration of air injection are kept constant. The effect of the air injection pressure on the transient performance of turbocharged diesel engine is investigated by changing injection pressure from no air injection to 2, 4, and 6 bar respectively. 
The results show that when the air injection system is used the time taken for the system to reach a steady state is significantly reduced. This means that the air pressure going into the cylinders is higher at an earlier stage of the process. Following the air-fuel equivalence ratio was kept at adequately high values during the early cycles of the transient event, preventing combustion deterioration and establishing faster turbocharger response. As a result, the time taken for the engine speed, turbocharger speed, boost pressure was reduced. The higher the pressure of air injection the shorter the time needed to reach the final steady state conditions.

Results also show that as the injection pressure increases, the reduction on the smoke level increases at all initial loading due the increase of the quantity of air during combustion. A reduction of $30 \%$ to $40 \%$ is noticed at injection pressure of 6 bar at different initial loading.

In load acceptance tests, results show that when the air injection system is used the time taken for the system to reach a steady state is significantly reduced. This means that the air pressure going into the cylinders is higher at an earlier stage of the process. Following the air-fuel equivalence ratio was kept at adequately high values during the early cycles of the transient event, preventing combustion deterioration and establishing faster turbocharger response. As a result, the engine response time was decreases. The higher the injection pressure, the lower the maximum speed droop and the shorter the recovery period up to the final equilibrium.

Also, as the injection pressure increases, the reduction on the smoke level increases at all initial loading. Smoke level reduction of $60 \%$ is noticed at injection pressure of 6 bar at $20 \%$ initial loading due the decrease of the equivalence ratio during combustion

\section{References}

1. Rakopoulos C.D. and Giakoumis, E.G. " Diesel Engine Transient Operation", Springer -Verlag London Limited", 2009

2. Rakopoulos, C.D., Giakoumis, E.G. " Review of Thermodynamic Diesel Engine Simulations under Transient Operating Conditions" SAE 2006-01-0884.

3. Winterbone, D.E., Benson, R.S., Closs, G.D. and Mortimer, A.G., "A Comparison Between Experimental and Analytical Transient Test Results for a Turbocharged Diesel Engine", Proceedings of the Institution of Mechanical Engineers, Vol. 190, pp. 267 276, 1976.

4. Lee, C. S. and N Choi , N.J.," A Study on the Characteristics of Transient Response in a Turbocharged Diesel Engine" SAE Paper No. 912461, 1991.

5. Matsura, Y., Nakazawa, N. and Kobayashi " Effect of various methods for improving vehicles startabilityand transient response of turbocharged diesel engine" SAE 92004,1992.

6. Zellbeck, H., Friedrich, J. and Berger, C., "Electrically Assisted Turbocharging as a New Boosting Concept", Motortechnische Zeitschrift, Vol. 60, No. 6, pp. 386-391, 1999 (in German).

7. Filipi, Z., Wang, Y. and Assanis, D., " Effect of Variable Geometry Turbine (VGT) on Diesel Engine and Vehicle System Transient Response', SAE 2001-01-1247

8. Katrašnik, T., Rodman, S., Trenc, F., Hribernik, A. and Medica, V., "Improvement of the Dynamic Characteristic of an Automotive Engine by a Turbocharger Assisted by an Electric Motor", ASME Transactions, Journal of Engineering for Gas Turbines and Power, Vol. 125, pp. 590-595, 2003.

9. Saulnier, S. and Guillain, S., "Computational Study of Diesel Engine Downsizing Using Two-Stage Turbocharging”, SAE Paper No. 2004-01-0929. 
10. Katrašnik, T., Medica, V. and Trenc, F., "Analysis of the Dynamic Response Improvement of a Turbocharged Diesel Engine Driven Alternating Current Generating Set", Energy Conversion and Management, Vol. 46, No. 18/19, pp. 2838-2855, 2005.

11. Banisoleiman, K., Smith, L.A. and French, B.A., "The Interaction of Diesel Engine Turbocharging and Tuned Inlet Manifold Systems Under Steady State and Transient Operation", Proceedings of the Institution of Mechanical Engineers, Part A, Journal of Power and Energy, Vol. 205, pp. 269-281, 1991.

12. Rakopoulos, C.D., Giakoumis, E.G., Hountalas, D.T. and Rakopoulos, D.C., "The Effect of Various Dynamic, Thermodynamic and Design Parameters on the Performance of a Turbocharged Diesel Engine Operating under Transient Load Conditions", SAE Paper No. 2004-01-0926.

13. Ledger, J.D., Benson, R.S. and Furukawa, H., "Improvement in Transient Performance of a Turbocharged Diesel Engine by Air Injection into the Compressor", SAE Paper No. 730665, 1973.

14. Boy, P. "Investigation of Several Influences on the Dynamic Performance of MediumSpeed Marine Diesel Engine, Pt. 1: Calculation Model“", Motortechnische Zeitschrift, Vol. 41, pp. 343-348, 1980, "Pt. 2: Influences of Different Factors on the Dynamic Performance“", Motortechnische Zeitschrift, Vol. 41, pp. 491-496, 1980 .

15. Fayed,H.A." Diesel Engine Turbocharger Match.Evaluation And Improvement" Ph.D. thesis, MTC, Cairo, 1995.

16. Lee, C. S. and N Choi , N.J., "Effect of air injection on the characteristics of transient response in aturbocharged diesel engine", Int. J. Therm. Sci. 41 (2002) 63-71.

17. Gilkes, O.S. and Mishra, Rakesh " Comparison of passive and active methods for improving transient performance of turbocharged engine system"s. In: Proceedings of Computing and Engineering Annual Researchers' Conference 2006: CEARC'06. University of Huddersfield, Huddersfield, pp. 1-6.

18. Gilkes, O.S., Mishra, Rakesh, Rao, H.V. and Fieldhouse, John D. (2007) Transient response of turbocharged diesel engine for transient operation using air injection assist system. In: Proceedings of Computing and Engineering Annual Researchers' Conference 2007: CEARC'07. University of Huddersfield, Huddersfield, pp. 1-7. 


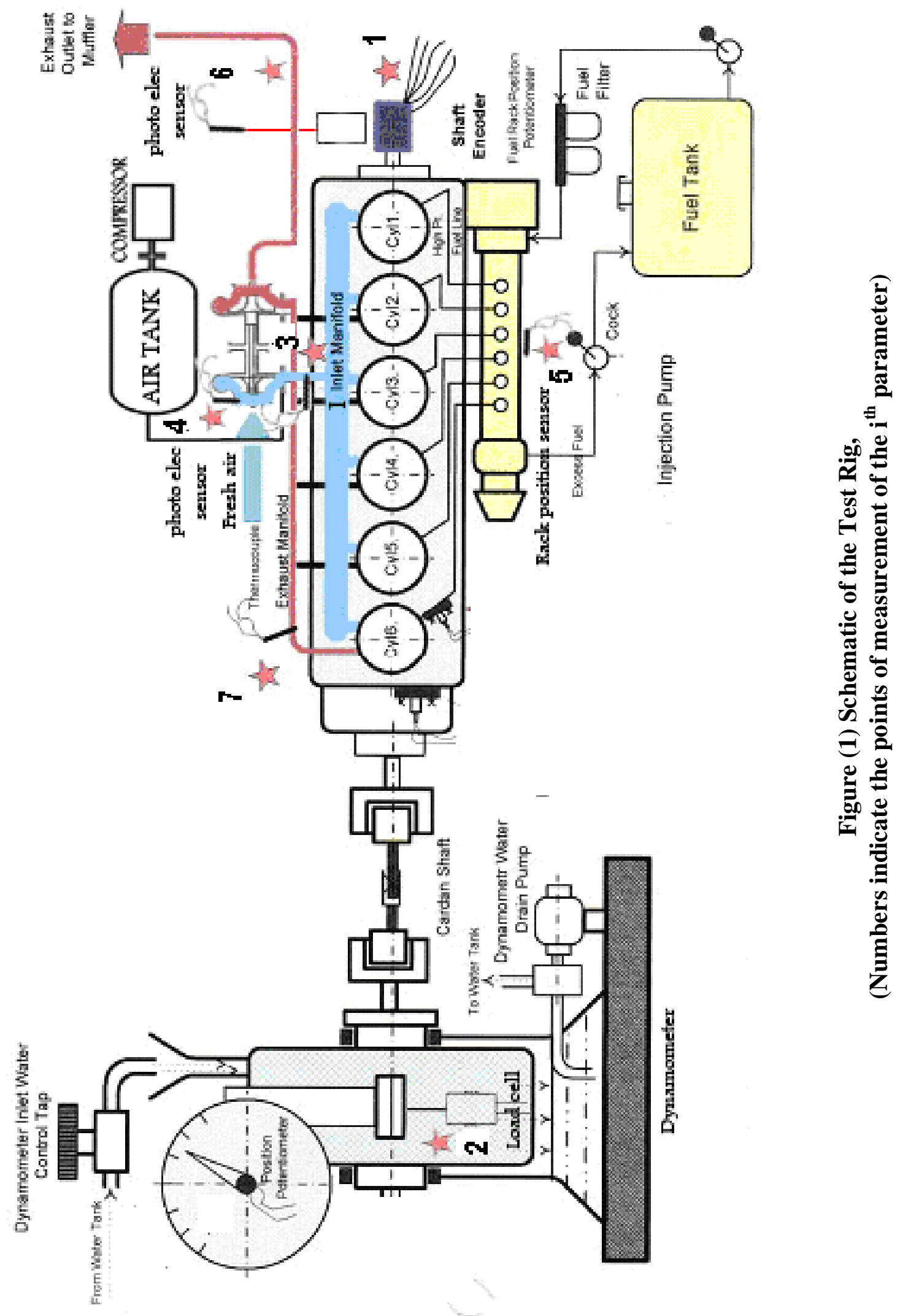




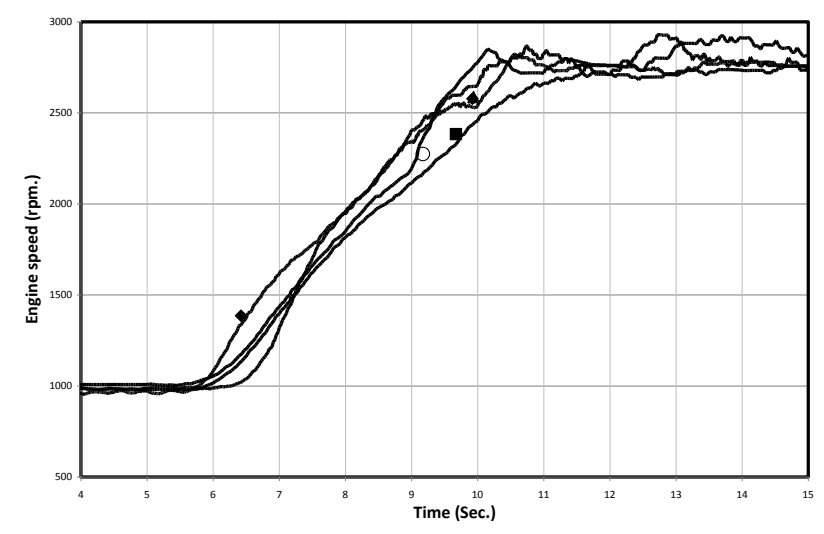

A: Initial brake torque of 27 N.m( $10 \%$ load)

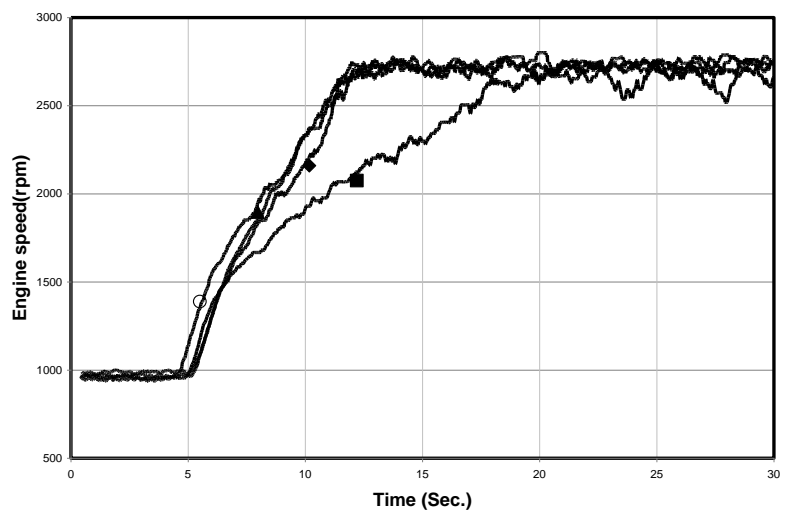

B: Initial brake torque of 81 N.m( $30 \%$ load)

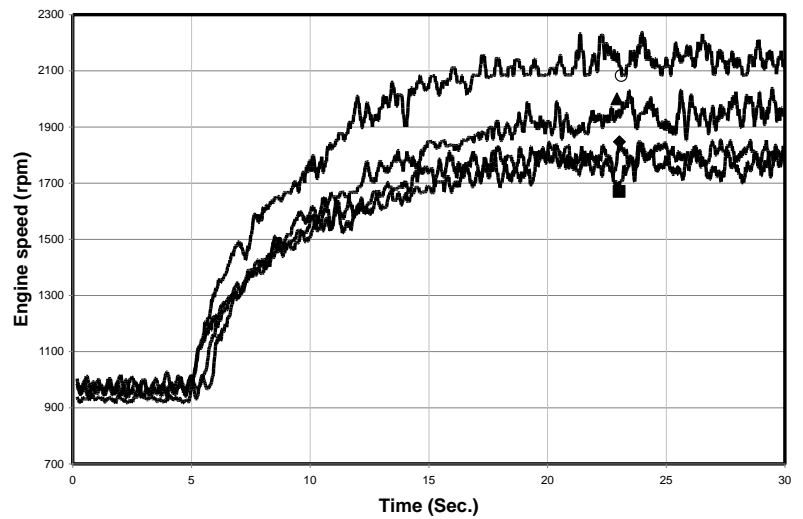

C: Initial brake torque of 135 N.m( $50 \%$ load)

Figure (2): Effect of the pressure of injected air on engine speed at different initial loads during acceleration test 


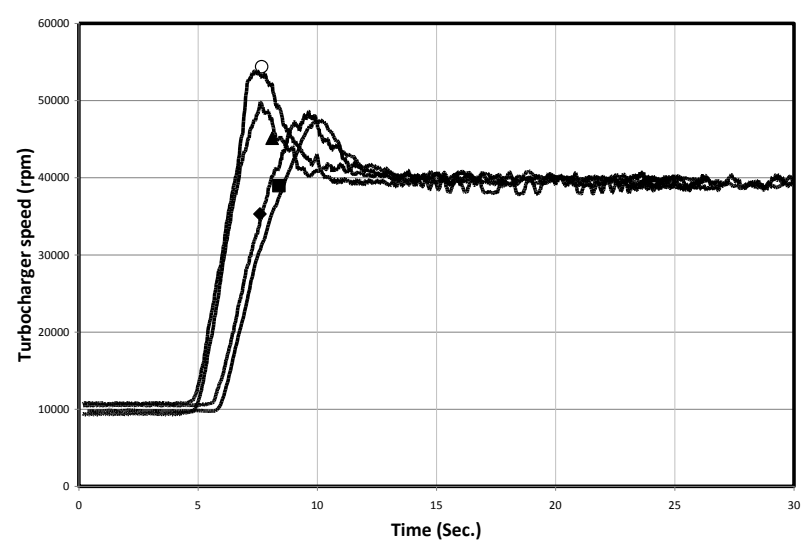

A: Initial brake torque of 54 N.m( $20 \%$ load)

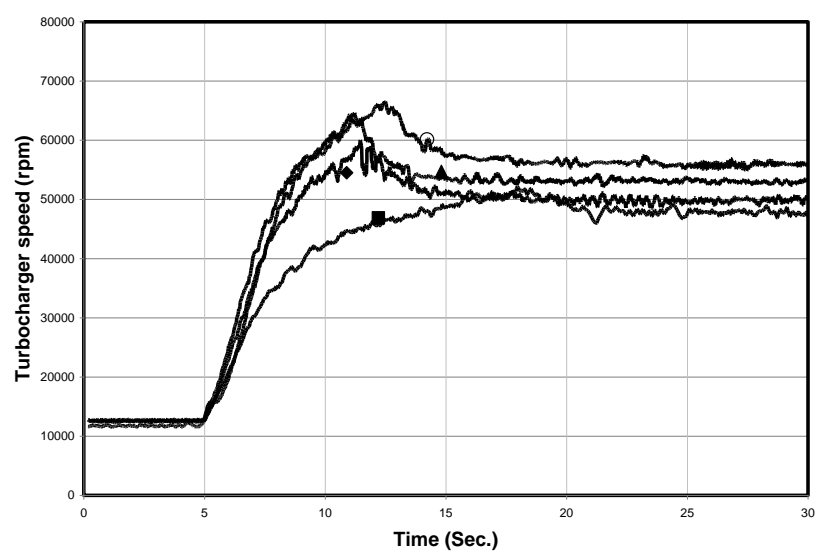

B: Initial brake torque of 81 N.m( $30 \%$ load)

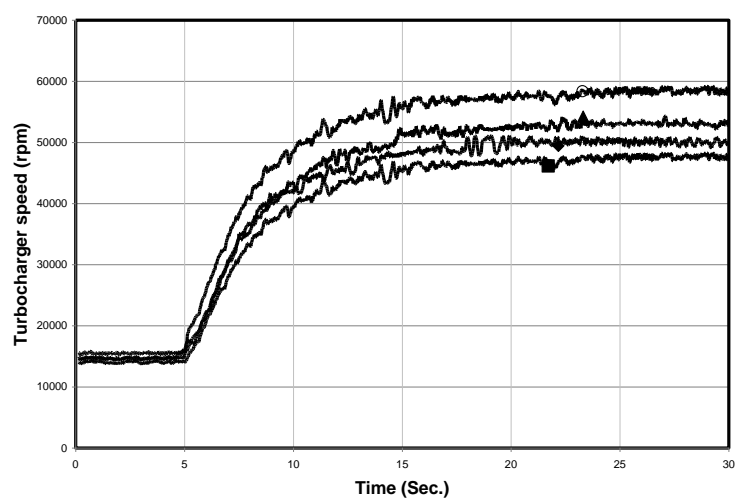

C: Initial brake torque of 135 N.m( $50 \%$ load)

- No air injection

- Air injection at 2 bar

Air injection at 4 bar

OAjr injection at 6 bar

Figure (3): Effect of the pressure of injected air on turbocharger speed at different initial load during acceleration test. 


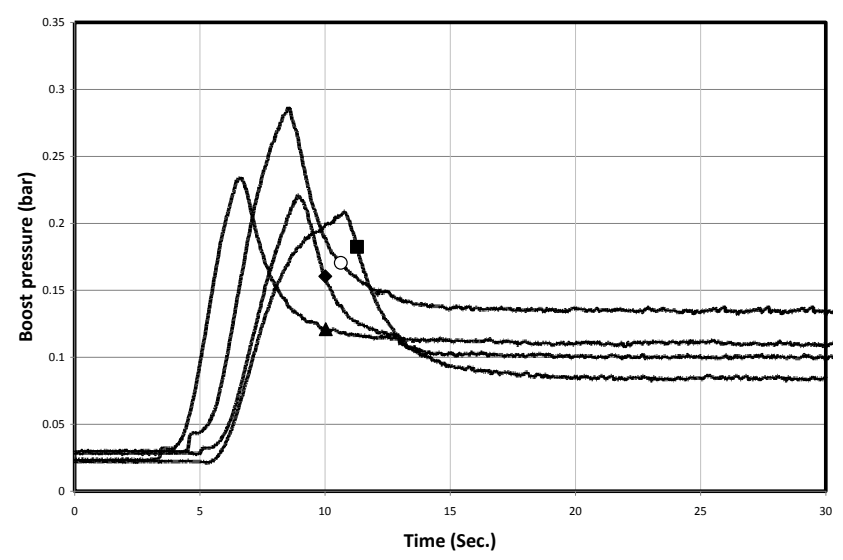

A: Initial brake torque of 27 N.m( $10 \%$ load)

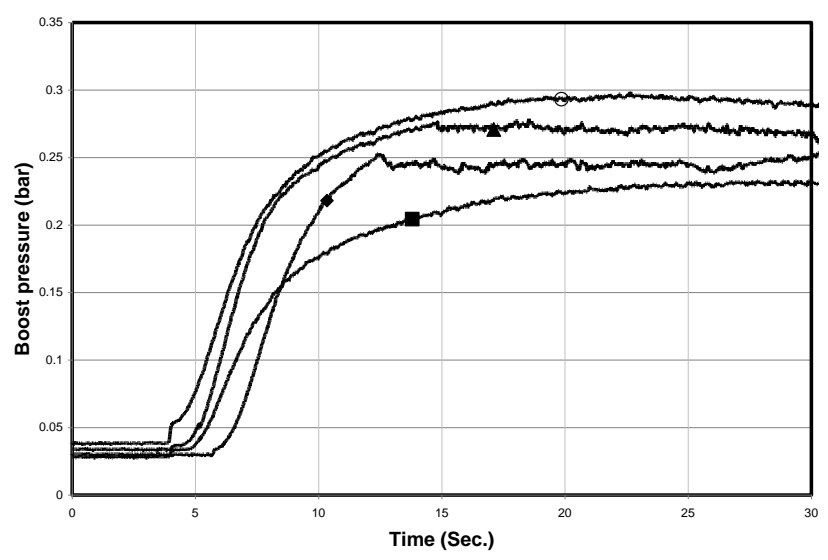

B: Initial brake torque of 81 N.m( $30 \%$ load)

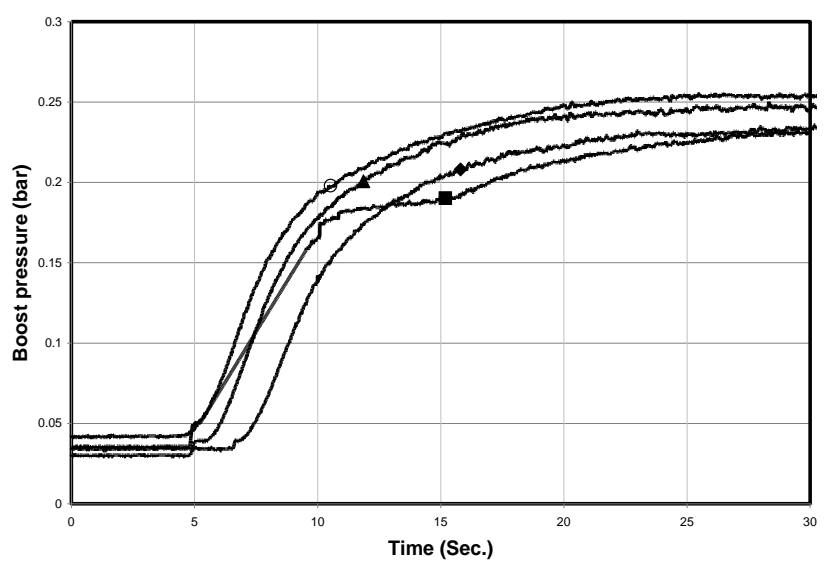

C: Initial brake torque of 135 N.m( $50 \%$ load)

- No air injection

- Air inje ction at 2 bar

$\boldsymbol{\Delta}$ Air injection at 4 bar

Q Air injection at 6 bar

Figure (4): Effect of the pressure of injected air on the boost pressure at different initial load during acceleration test. 


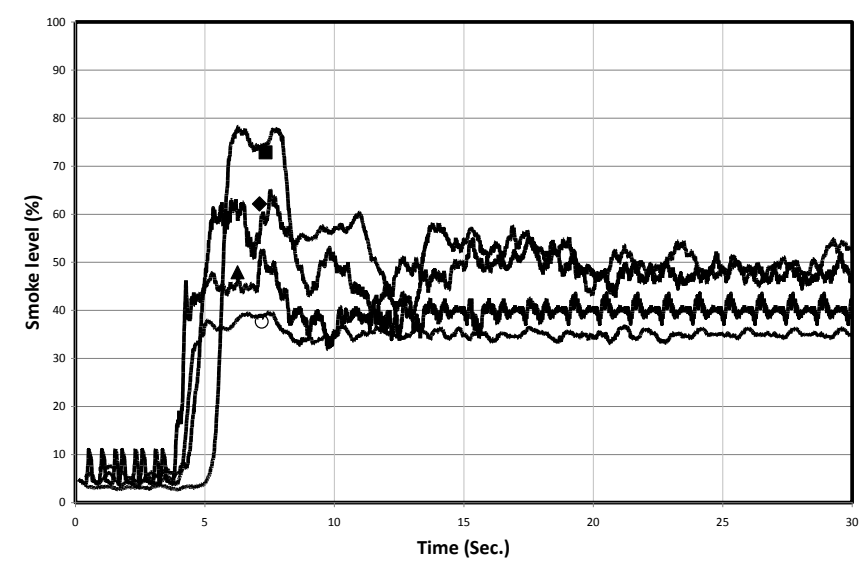

A: Initial brake torque of 27 N.m( $10 \%$ load)

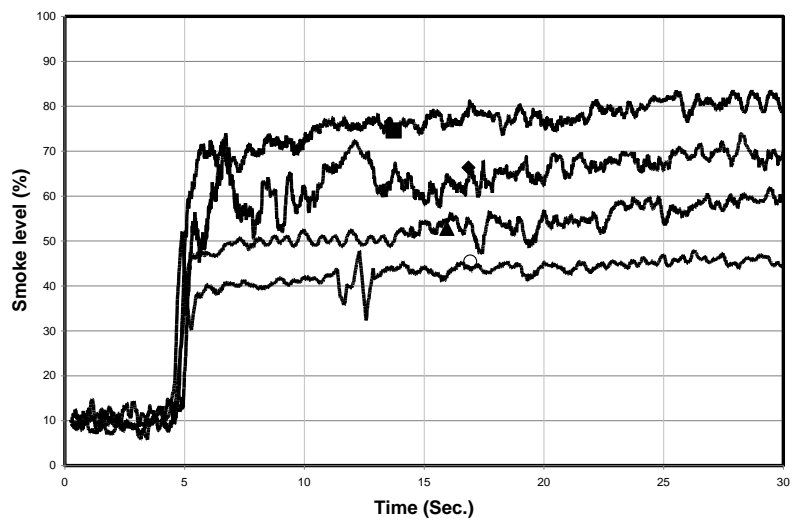

B: Initial brake torque of 81 N.m( $30 \%$ load)

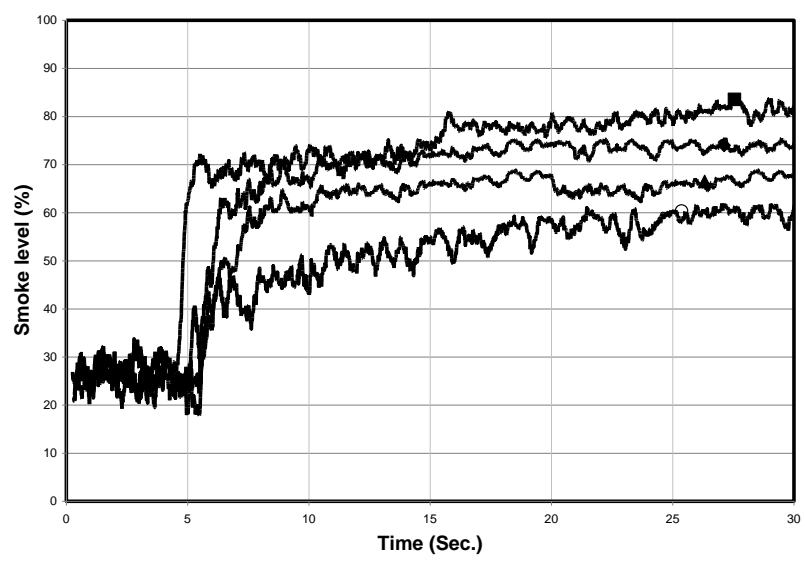

C: Initial brake torque of 135 N.m( $50 \%$ load)

Figure (5): Effect of the pressure of injected air on the smoke level at different initial load during acceleration test. 


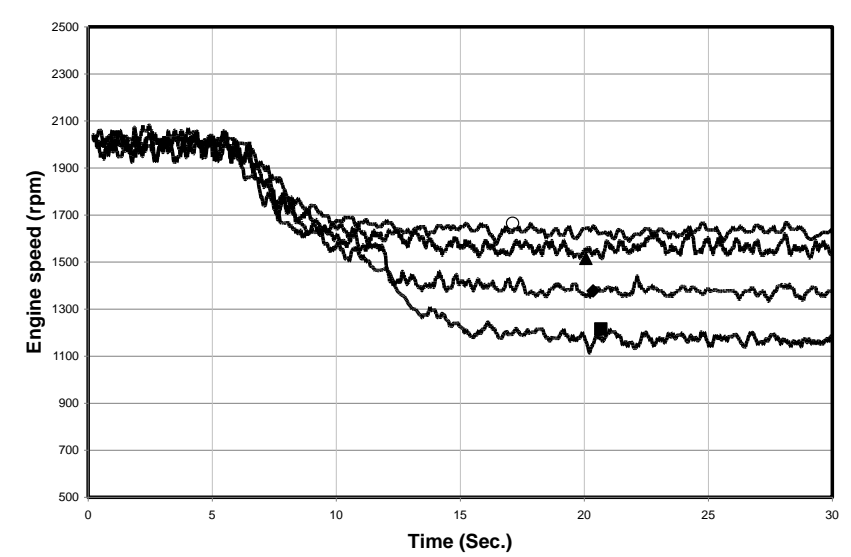

A: Initial brake torque of 54 N.m( $20 \%$ load)

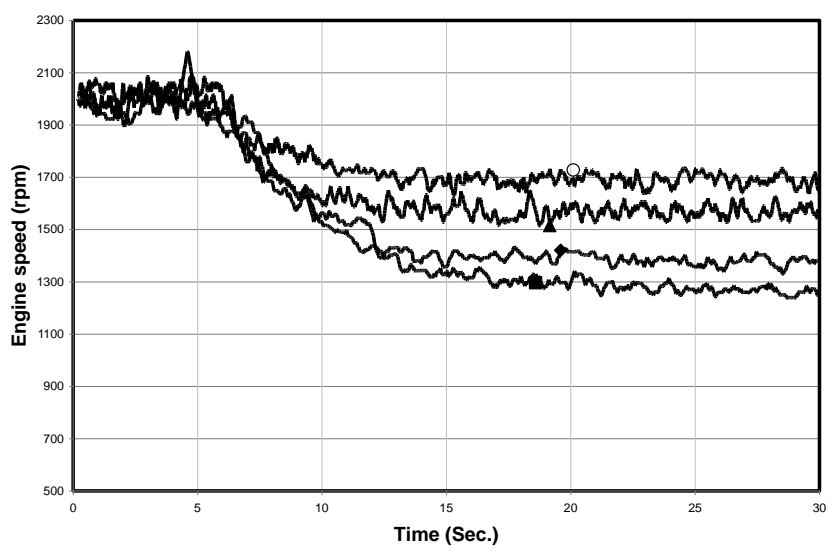

B: Initial brake torque of 81 N.m( $30 \%$ load)

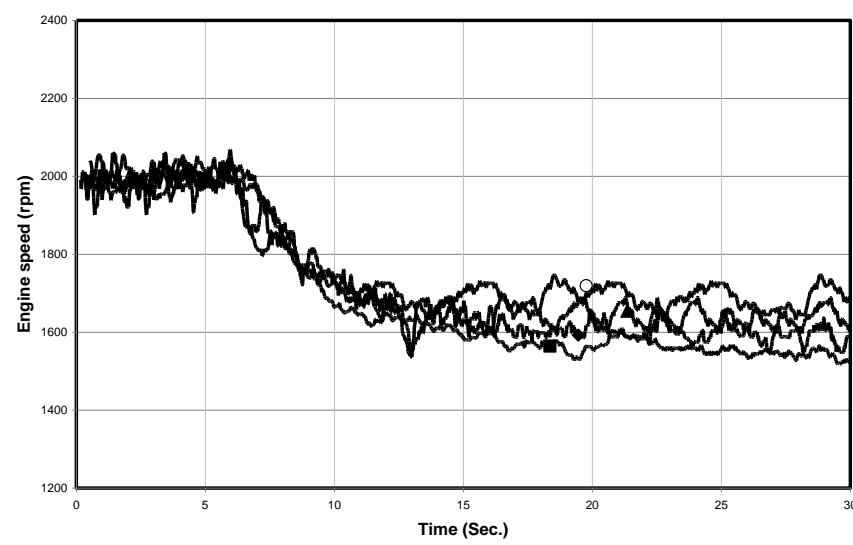

C: Initial brake torque of 135 N.m( $50 \%$ load)

Figure (6): Effect of the pressure of injected air on the engine speed at different initial load during load acceptance test. 


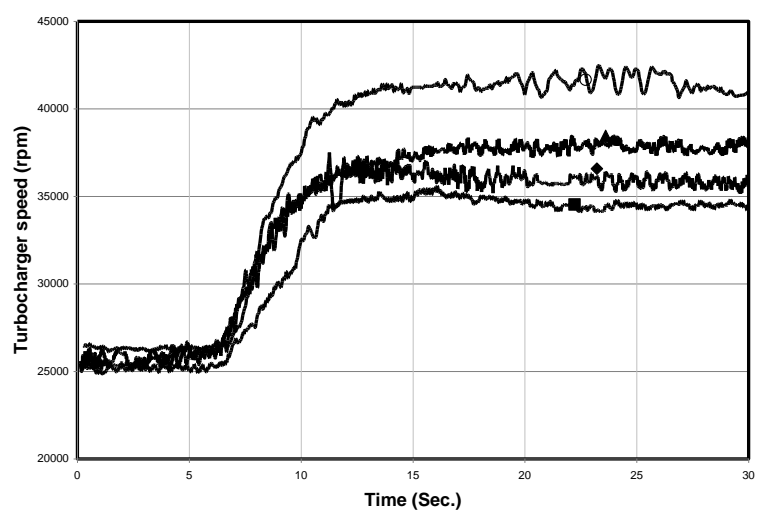

A: Initial brake torque of 54 N.m( $20 \%$ load)

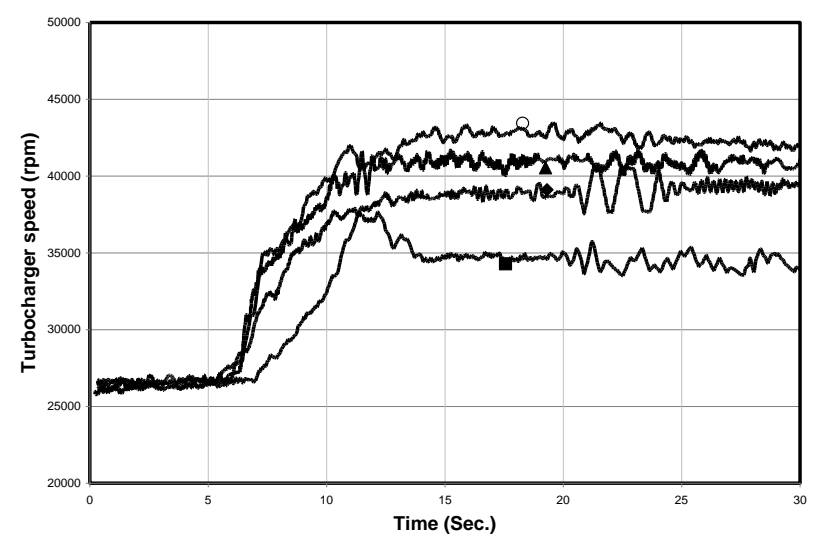

B: Initial brake torque of 81 N.m( $30 \%$ load)

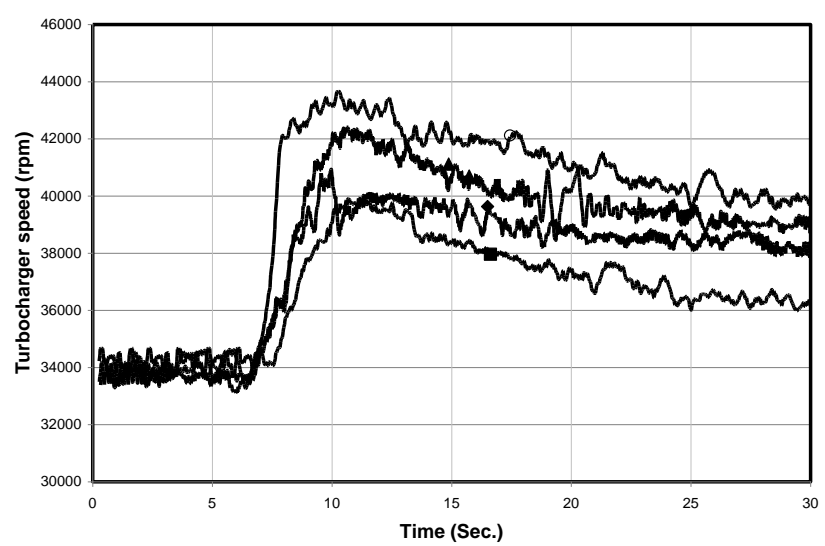

C: Initial brake torque of 135 N.m( $50 \%$ load)

Figure (7): Effect of the pressure of injected air on the turbocharger speed at different initial load during load acceptance test. 


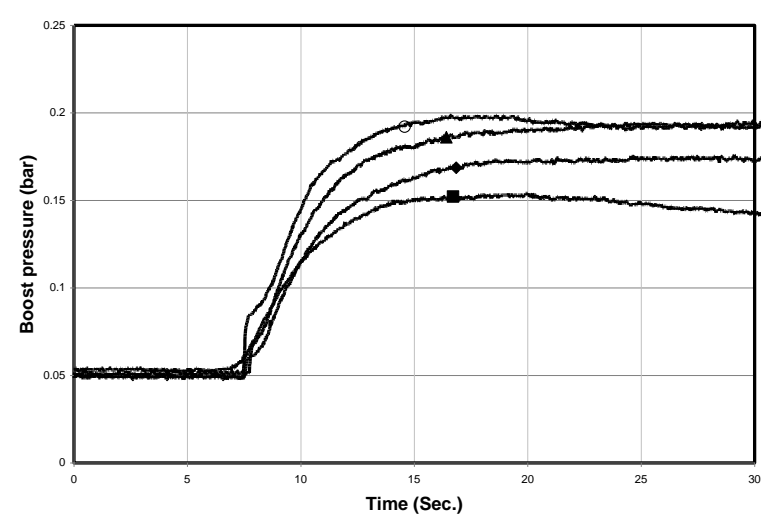

A: Initial brake torque of 54 N.m( $20 \%$ load)

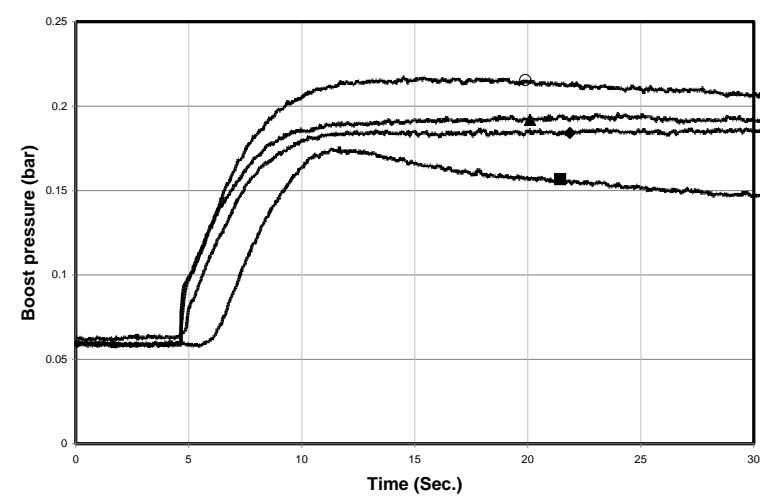

B: Initial brake torque of 81 N.m( $30 \%$ load)

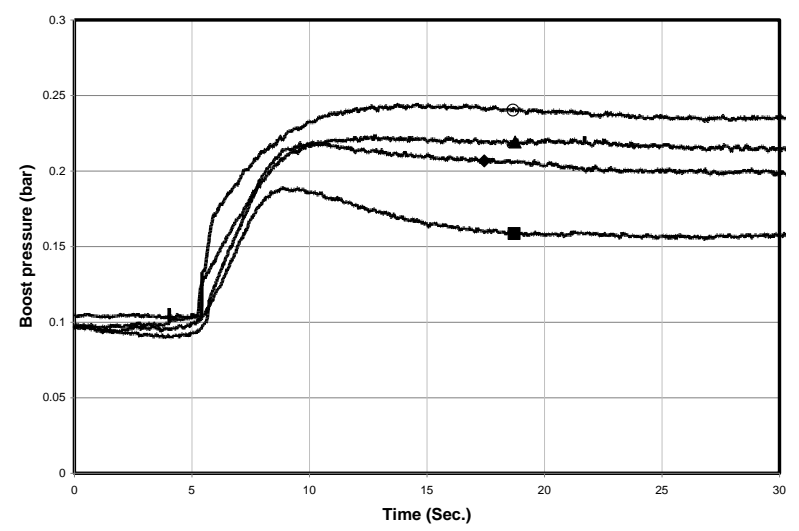

C: Initial brake torque of 135 N.m( $50 \%$ load)

Figure (8): Effect of the pressure of injected air on the boost pressure at different initial load during load acceptance test. 


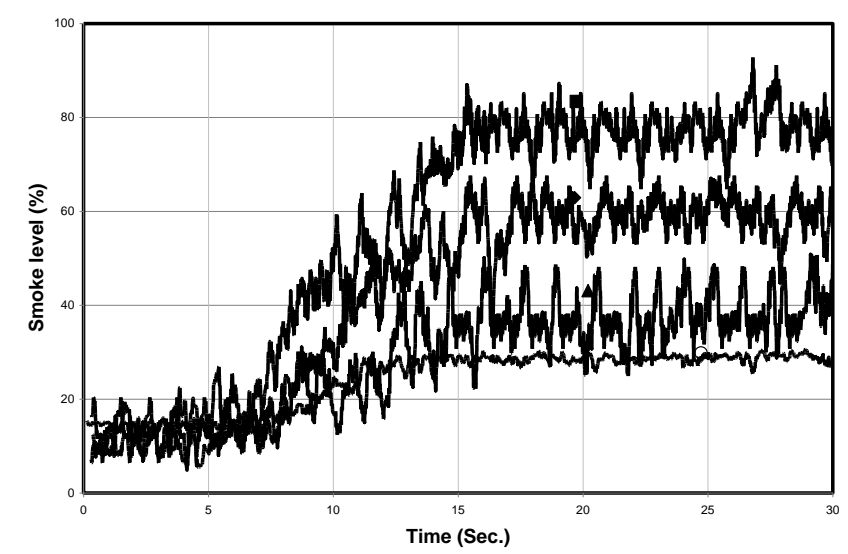

A: Initial brake torque of 54 N.m( $20 \%$ load)

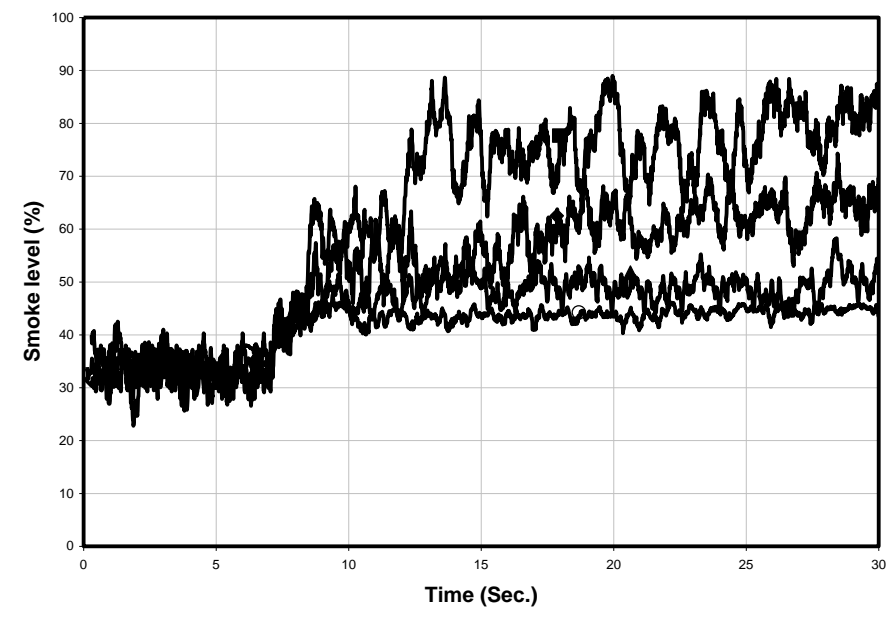

B: Initial brake torque of 81 N.m( $30 \%$ load)

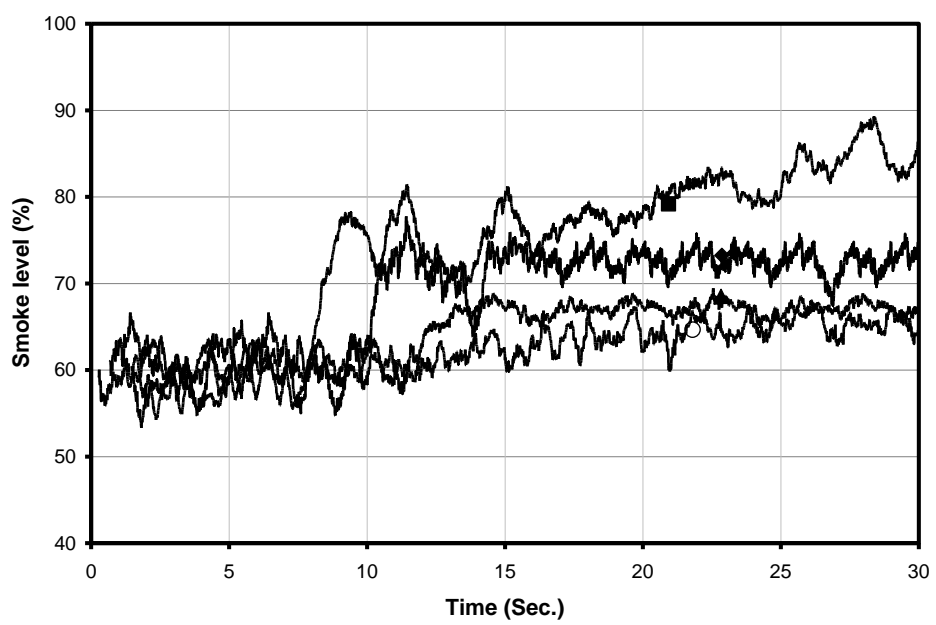

C: Initial brake torque of 135 N.m( $50 \%$ load)

Figure (9): Effect of the pressure of injected air on the smoke level at different initial load during load acceptance test. 